\title{
Nutrition for Special Populations: Young, Female, and Masters Athletes
}

\author{
Ben Desbrow \\ Griffith University \\ Mark Tarnopolsky \\ McMaster University Medical Centre
}

\author{
Nicholas A. Burd \\ University of Illinois at Urbana-Champaign \\ Daniel R. Moore \\ University of Toronto
}

\author{
Kirsty J. Elliott-Sale \\ Nottingham Trent University
}

\begin{abstract}
Adolescent, female, and masters athletes have unique nutritional requirements as a consequence of undertaking daily training and competition in addition to the specific demands of age- and gender-related physiological changes. Dietary education and recommendations for these special population athletes require a focus on eating for long-term health, with special consideration given to "at-risk" dietary patterns and nutrients (e.g., sustained restricted eating, low calcium, vitamin D and/or iron intakes relative to requirements). Recent research highlighting strategies to address age-related changes in protein metabolism and the development of tools to assist in the management of Relative Energy Deficiency in Sport are of particular relevance to special population athletes. Whenever possible, special population athletes should be encouraged to meet their nutrient needs by the consumption of whole foods rather than supplements. The recommendation of dietary supplements (particularly to young athletes) overemphasizes their ability to manipulate performance in comparison with other training/dietary strategies.
\end{abstract}

Keywords: adolescent, age, gender, health

Athletics provides many benefits to people, including regular physical activity, social interaction, and the development of selfidentity and self-esteem. How the International Association of Athletics Federations supports a positive lifelong connection to athletic pursuits for both men and women is fundamental to ongoing participation in track-and-field events. Responsibility for the provision of appropriate nutrition care to young, female, and/or masters athletes is shared among the sport's leaders, coaches, parents, teachers, and the athletes themselves. This review incorporates aspects of physiology, psychology, training science, and sociology to describe our current understanding of the nutrition priorities for these special population athletes.

\section{Physiological Changes in Adolescent Athletes}

Adolescence is a period of significant growth and physical development that includes altered body composition, metabolic and

Desbrow is with the School of Allied Health Sciences, Griffith University, Gold Coast, Queensland, Australia. Burd is with the Dept. of Kinesiology \& Community Health, University of Illinois at Urbana-Champaign, Urbana, IL, USA. Tarnopolsky is with Neuromuscular and Neurometabolic Clinic, McMaster University Medical Centre, Toronto, Ontario, Canada. Moore is with the Faculty of Kinesiology and Physical Education, University of Toronto, Toronto, Ontario, Canada. Elliott-Sale is with Musculoskeletal Physiology Research Group, Sport, Health and Performance Enhancement (SHAPE) Research Centre, Nottingham Trent University, Nottingham, United Kingdom. Desbrow (b.desbrow@griffith.edu.au) is corresponding author. hormonal fluctuations, maturation of organ systems, and establishment of nutrient deposits, which all may affect future health (Sawyer et al., 2012). In terms of nutrition, adolescence is also an important time in establishing an individual's lifelong relationship with food, which is particularly important in terms of the connection between diet, exercise, and body image (Desbrow et al., 2014). It is also important to recognize that athletic performance development is nonlinear, with success at junior competitions infrequently translating to success at Olympic or World Athletics Championships (Pizzuto et al., 2017).

During adolescence, adequate energy is required to meet both the growth and development needs of the individual, as well as the substrate demands associated with general physical activity, training, and competition (Aerenhouts et al., 2011). Although group estimates of energy expenditure in adolescent athletes have been reported (i.e., males $\sim 3,640 \pm 830 \mathrm{kcal} /$ day and females $\sim 3,100 \pm$ $720 \mathrm{kcal} / \mathrm{day}$; Carlsohn et al., 2011), it is difficult to define the individual energy requirements of an adolescent athlete with precision due to metabolic variability within and between individuals (Petrie et al., 2004) and methodological difficulties in estimating both energy intake and energy expenditure (Burke et al., 2001). Furthermore, the energy expenditure associated with the exercise commitments of adolescent athletes may vary substantially due to many factors (e.g., training and competition load, seasonal variation, participation in more than one competitive sport, and concurrent compensatory sedentary behaviors).

The energy needs for growth are a component of the energy requirements of adolescent athletes and consist of two parts: The energy deposited in growing tissues and the energy expended to 
synthesize those tissues (Torun, 2005). The energy deposited in growing tissues is small and has been commonly estimated as $8.6 \mathrm{~kJ} / \mathrm{g}$ of daily weight gain (e.g., for a 15-year-old male gaining $6 \mathrm{~kg} /$ year $=\sim 140 \mathrm{~kJ} /$ day; World Health Organization, 1983). The energy expended to synthesize new tissues is incorporated in measures of total energy expenditure, such as doubly labeled water. These measures indicate that the energy changes associated with physical activity and/or athletic training are likely to have a much greater influence on energy demands than the increases associated with growth (Torun, 2005). Despite this, it is important to acknowledge that resting metabolic rate is higher in adolescent athletes than adults, and standard predictive equations often underestimate resting metabolic rate compared with measured (up to $300 \mathrm{kcal} /$ day) rate in adolescents (Loureiro et al., 2015).

In additional to enhancing the response to the stimulus of exercise training (Witard et al., 2018), adolescents have additional protein requirements to support general growth and development (Aerenhouts et al., 2011). Total energy intake is important to consider in the assessment of protein requirements because inadequate energy intake will cause protein to be used as a substrate for energy, potentially reducing its availability for its primary functions (Campbell et al., 2007; Petrie et al., 2004). It appears that protein recommendations do not have to increase during periods of peak growth in adolescent athletes (Aerenhouts et al., 2013).

The duration and intensity of exercise sessions determine carbohydrate utilization patterns and refueling requirements (Burke et al., 2017). There is little evidence to suggest that the utilization of carbohydrate in adolescents differs substantially from those of adults (Desbrow et al., 2014).

Young individuals appear to have a similar capacity to adults in dealing with thermal loads and exercise-tolerance time during exercise in the heat (Rowland et al., 2008). However, the mechanisms by which young individuals dissipate heat loads during exercise differ from those of adults (Falk \& Dotan, 2008). Children and adolescents appear to rely more on peripheral blood redistribution (radiative and conductive cooling) rather than sweating (evaporative cooling) to maintain thermal equilibrium (Falk \& Dotan, 2008). There is also evidence that adolescents who undertake regular training adapt by enhanced peripheral vasodilation (Roche et al., 2010), which is likely to improve nonevaporative cooling. Although the timing of the transition from a child-like to an adult-like thermoregulatory mechanism is likely to be related to pubertal development, it appears that these changes do not become physiologically evident until puberty has been completed (Falk et al., 1992).

\section{Nutritional Needs for Adolescent Athletes}

Suggested energy requirements (incorporating total energy expenditure plus energy deposited in growing tissues) for adolescent populations with different levels of physical activity and/or training have been published (Torun, 2005). It appears that low energy availability (EA) in adolescent athletes undertaking heavy training is common (Muia et al., 2016). This may lead to a number of undesirable health consequences, including delayed puberty, menstrual irregularities, poor bone health, short stature, the development of disordered eating behaviors, and increased risk of injury. Furthermore, in females $\leq 14$ years gynecological age, the effects of low EA may be more pronounced (Loucks, 2006). Conversely, some athletes (particularly in the throwing events) demonstrate anthropometric characteristics consistent with the potential for excessive energy intakes (Hirsch et al., 2016).
Clearly, participation in sport can play an important role in supporting psychological well-being and developing a healthy physical self-image (Ekeland et al., 2005). However, increased rates of disturbed eating attitudes and behaviors are evident in sports that emphasize leanness for optimal performance (Torstveit et al., 2008). It is prudent to suggest that many adolescent athletes will require the knowledge, skills, and support to develop a healthy lifelong relationship with food. Although a number of practical methods to assess the adequacy of EA exist (Mountjoy et al., 2015), these may further serve to focus attention on restrictive dietary behaviors. Consequently, it is appropriate that professional associations advocate for the use of nondieting strategies (SundgotBorgen et al., 2013) when addressing weight concerns in young athletes. In addition, the use of training strategies designed to manipulate an adolescent athlete's physique independent of performance is discouraged, as is any divisive weight-related comments or bullying within athletic environments (Desbrow et al., 2014).

Provided that energy needs are met, protein intake at $\sim 0.11 \mathrm{~g} \cdot \mathrm{kg}^{-1} \cdot \mathrm{hr}^{-1}$ during postexercise recovery or the equivalent of $\sim 1.5 \mathrm{~g} \cdot \mathrm{kg}^{-1} \cdot \mathrm{day}^{-1}$ (e.g., $\sim 0.3 \mathrm{~g}$ protein $/ \mathrm{kg} \times 5$ meal times) should be sufficient to replace any exercise-induced amino acid oxidative losses, enhance whole-body net protein balance, and support the normal growth and development of adolescent athletes (Aerenhouts et al., 2013; Mazzulla et al., 2018).

Dietary carbohydrate needs should be considered in light of the training loads and competition characteristics that are typically undertaken by adolescent athletes. These can differ from those undertaken by adult athletes in a number of ways. First, adolescent athletes may be involved with numerous organizations (e.g., schools, clubs, and regions) that create different competition frequencies and formats, such as sports carnivals, representative events, and trials. It is also common for aspiring adolescent athletes to participate in a number of different sports. These different energy demands and subsequent carbohydrate requirements must be considered, particularly when the participation in different sports is concurrent.

There is some evidence suggesting an increased prevalence of heat illness associated with sport and activity in younger athletes (Centers for Disease Control and Prevention, 2011). Heat illness may be influenced by poor hydration status along with other factors, such as undue physical exertion, insufficient cooling between exercise bouts, and inappropriate choices of clothing, including uniforms. Unfortunately, there is no evidence to determine the extent to which (if at all) fluid intake may modulate the risk of heat illness in adolescent athletes. This is because fluid monitoring studies on children and adolescents at risk of heat illness are scarce and often fail to report participants who actually experience heat illnesses (Somboonwong et al., 2012). By contrast, field studies indicate that adolescent athletes can experience significant deficits in fluid ( $>4 \%$ body weight) during training and competition in the heat (Aragon-Vargas et al., 2013). Fluid shifts of this magnitude have the potential to effect exercise performance. It appears prudent, then, to apply the same fluid intake guidelines indicated for adult athletes (Casa et al., 2018).

\section{Physiological Changes in Masters Athletes}

Aging is associated with a loss of muscle mass and strength/ function that is collectively referred to as sarcopenia. Muscle size and strength generally peaks at 20-30 years and begins to decline in middle age ( $\sim 0$ to 50 years), with an acceleration in 
older adulthood (generally $>70-75$ years). Decline in muscle mass is markedly influenced by physical activity, with inactive and sedentary individuals experiencing a more rapid decline that is generally preceded by the development of "anabolic resistance" (i.e., a reduced ability to utilize dietary amino acids for muscle protein synthesis; Moore, 2014; Witard et al., 2018). Physical activity, especially resistance exercise, can counteract the deleterious effects of inactivity in aging and, therefore, it is unclear if masters athletes experience similar rates of anabolic resistance as the general population. The loss of muscle mass with age may be related to a decrease in total muscle fibers (Doering, Jenkins, et al., 2016), perhaps secondary to a loss of motor neurons (Hunter et al., 2016) and muscle fiber size (especially of Type II fibers; Nilwik et al., 2013), although lifelong masters athletes may experience little change in muscle fiber composition (Trappe et al., 1995) and an attenuated decline in muscle strength relative to their sedentary peers (Crane et al., 2013).

It has been reported that up to $\sim 30 \%$ of male athletes over age 50 years have some level of testosterone deficiency (Di Luigi et al., 2010), which would be consistent with a condition sometimes referred to as "andropause" or "exercise-hypogonadal male condition." Although providing supplemental testosterone to hypogonadal men improves muscle strength (Bhasin et al., 1997) and increases red blood cell mass (Traustadottir et al., 2018), currently, therapeutic use exemptions are only approved for hypogonadism with an organic etiology (excludes age-related hypogonadism; World Anti-Doping Agency, 2018). Similarly, the decline in estrogen with menopause is associated with a more rapid decline in muscle mass (Chen et al., 2005), and estrogen is associated with an increase in lipid oxidation with sparing of both glycogen and protein (Tarnopolsky, 2008). Therefore, hormonal replacement therapy in postmenopausal women may confer some ergogenic benefit to female masters athletes. Concomitant with an agingassociated decline in muscle and lean body mass (LBM), there is a general increase in adiposity with age. Thus, sports that require a high strength-to-mass ratio may be affected, to a greater extent, with age.

The age of peak performance in athletics is relatively stable across sport disciplines and generally occurs in early to mid-30s (Tanaka \& Seals, 2003). After this age, athletic performance steadily decreases up to $\sim 50$ to 60 years of age, after which the declines accelerate in a curvilinear fashion (Tanaka \& Seals, 2003). Although some of the decline in endurance performance may reflect a decrease in training volume and/or intensity in masters athletes (Tanaka \& Seals, 2003), there are also documented physiological changes that can underpin these performance changes. For example, maximal oxygen consumption decreases $\sim 10 \%$ per decade after the age of $\sim 25$ years irrespective of fitness level (Hawkins \& Wiswell, 2003). This decline in $\mathrm{VO}_{2}$ peak may be related to both central (maximal heart rate and stroke volume) and peripheral (arteriovenous oxygen difference) factors. One of the most common findings in endurance athletes is an age-related reduction in maximal heart rate of $\sim 3 \%$ to $5 \%$ per decade (Hawkins \& Wiswell, 2003). Although the physiological basis is not clear, stroke volume may also be moderately reduced in older compared with younger endurance athletes (Tanaka \& Seals, 2003) who can compound the impact of an age-related reduction in maximal heart rate on cardiac output. Peripherally, older adults experience a reduction in capillaries per fiber but, due to the general reduction in fiber size, may have slightly greater capillaries per fiber area, which would help with muscle oxygen delivery. There is a consistent decline in mitochondrial capacity with aging seen in most studies, albeit some show no effect (Proctor et al., 1995). The absolute $\mathrm{VO}_{2}$ at lactate threshold may be reduced in masters athletes, but the percentage of $\mathrm{VO}_{2}$ at lactate threshold is similar to or slightly greater than younger athletes (Marcell et al., 2003). Thus, although peripheral arteriovenous $\mathrm{O}_{2}$ differences can contribute $\sim 30 \%$ to the age-related reduction in $\mathrm{VO}_{2}$ peak (Tanaka \& Seals, 2003), a reduction in cardiac output, likely secondary to decreases in maximal heart rate, is the variable primarily responsible for the reduced aerobic capacity in masters athletes. Finally, older adults have lower muscle glycogen and GLUT4 content compared with younger adults; however, they can increase these with endurance exercise training (Cartee, 1994).

Masters athletes involved in sports that require high strength and/or muscle power are likely to experience gradual decreases in exercise performance. The loss of strength with age is related in part to the reduction in muscle fiber size and motor units, especially of the high-force Type II fibers (Hunter et al., 2016). When normalized to total muscle or fiber area, there is little difference in specific force or inherent contractile properties (e.g., peak torque, contraction velocity, peak power) of type I and IIa fibers in older compared with younger adults (Trappe et al., 2003), suggesting the loss of muscle strength with age may be due primarily to the quantity rather than quality of skeletal muscle. However, neuromuscular changes proximal to the muscle fiber may also contribute to the loss of strength and/or ability to produce high-velocity force, such as reductions in neuronal conduction velocity, motor unit discharge rates, and/or neuromuscular junction stability (Hunter et al., 2016).

\section{Nutritional Needs for Masters Athletes}

Although individuals can commence master athletics competition at 35 years (World Masters Athletics), the majority of research investigating metabolic and nutritional requirements in the older athlete are done in those aged $>55$ years. Of particular interest are investigations focused on the requirements for attaining and/or maintaining strength and/or power (field sports and sprinting) and endurance (track events $\geq 800 \mathrm{~m}$ ). The primary outcomes of interest for strength and/or power athletes will be studies related to enhancement of LBM, strength, and/or performance in relevant tasks. For endurance events, the main outcome variables for consideration will be improvements in performance in endurancespecific sport or changes in body composition/metabolism that would influence performance.

Given the well-known loss of muscle mass with human aging, it is particularly important for masters athletes to pay attention to dietary protein intake. The total protein intake for masters athletes trying to optimize strength and power gains during training should be $\geq 1.2 \mathrm{~g} \cdot \mathrm{kg}^{-1} \cdot \mathrm{day}^{-1}$ (Morton, Traylor, et al., 2018); however, this level can go up if energy intake is suboptimal, at the onset of an increased intensity/volume of exercise, or if the quality of the dietary protein is low (e.g., an unbalanced amino acid profile often associated with isolated plant-based proteins). It is important for the master athlete to try to consume high-quality protein (i.e., egg white, milk, fish, meats) or, if vegetarian, to try to get optimal amino acids balance via careful dietary review, ideally with a qualified sport nutritionist/dietitian. A broad distribution of protein ingestion also appears to positively influence net protein balance. For example, consuming protein shortly after exercise (Burd et al., 2012; Witard et al., 2018) and/or later in the day both positively impact the adaptive response (Holwerda et al., 2016), with these benefits appearing independent of acute exercise (Trommelen et al., 
2018). To optimize lean mass gains during resistance exercise, masters athletes should aim to consume meal protein intakes of $\sim 0.4 \mathrm{~g} / \mathrm{kg}$ of high-quality protein after the training bout and regularly throughout the day (e.g., 3-4 times) to meet a daily target of $\sim 1.5$ to $1.6 \mathrm{~g} \cdot \mathrm{kg}^{-1} \cdot \mathrm{day}^{-1}$ (Morton, Murphy, et al., 2018). When possible, whole-food sources of protein should be a target to practically acknowledge food matrix interactions, and other nutrient requirements, for optimizing the use of protein in the diet.

Several studies have found that male endurance athletes require $1.6-1.8 \mathrm{~g} \cdot \mathrm{kg}^{-1} \cdot \mathrm{day}^{-1}$ for optimal protein and/or amino acid homeostasis, with young women requiring $~ 25 \%$ lower intakes due to the estrogen-mediated decreases in amino acid oxidation (Witard et al., 2018). It is likely that postmenopausal master women would have protein requirements similar to that of men. Although the short-term effects of suboptimal protein intakes are unclear, it is possible that impaired mitochondrial biogenesis, less red blood cell expansion, and/or increased oxidation and/or repair/ remodeling of structural/regulatory proteins could all contribute to deleterious effects on endurance performance. Although the dietary protein intake required to support nitrogen balance is similar among late middle-aged athletes ( $~ 52$ years) compared with younger ( 27 years) athletes (Meredith et al., 1989), no study to date has specifically evaluated the protein requirement of older ( $>65$ years) masters athletes to maximize net whole-body or muscle protein accretion. Thus, although the "anabolic resistance" of aging at the muscle level may be mediated primarily by a reduction in physical activity, it is unclear if master endurance athletes require greater protein than their late middle-aged peers to support the adaptive response to exercise training.

Consequently, it is likely carbohydrate loading strategies will also work in masters athletes, provided they consume $>8.0 \mathrm{~g} \cdot \mathrm{kg}^{-1}$. day $^{-1}$ of carbohydrate. The latter suggestion is particularly important for female master endurance athletes, where the average carbohydrate intakes are often reduced (Doering, Reaburn, et al., 2016). There is no evidence that within- or postexercise carbohydrate supplementation recommendations for younger athletes would differ for masters athletes.

Finally, given the fact that even younger (18-39 years) elite and professional athletes have dental issues (i.e., pain in 30\%) that can affect performance (Gallagher et al., 2018), it is likely that such issues are even more prevalent in older athletes. Given concerns about enamel loss and the potential for thermal sensitivity and/or caries in those who regularly consume sport drinks (Venables et al., 2005), it is imperative that masters athletes engage in regular dental care.

\section{Physiological Differences Between Male and Female Athletes}

The ovarian hormones, estrogen and progesterone, are responsible for many of the sex differences observed in fuel metabolism. Unlike males, females experience changes to their reproductive hormonal milieu throughout their life span. The female reproductive cycle extends from menarche to the menopause in a circamensal rhythm, which ranges from 21 to 35 days (Cable \& Elliott, 2004). Strenuous athletic training, high exercise energy expenditure, low energy intake, or a combination of both that result in low EA, may affect the normal menstrual cycle, resulting in subclinical (shortened luteal phase defect and anovulation) and clinical (oligomenorrhea, primary and secondary functional hypothalamic amenorrhea) menstrual dysfunctions (Loucks, Verdun, \& Heath, 1998).
Apart from menopause (see "Nutritional Needs for Master Athletes"), the menstrual cycle is also disrupted by hormonal contraceptives, which downregulate endogenous estrogen and progesterone. Oral contraceptives, the most popular type of hormonal contraceptives, can differ in terms of estrogenic and progestogenic content (low and high dose) and the androgenicity and potency of progesterone. Recent investigations suggest that the use of combined oral contraceptives is associated with elevations in markers of oxidative stress and low-grade inflammation in athletic populations (Cauci et al., 2016, 2017). Furthermore, fluctuations in sex steroid hormones (via the menstrual cycle, pregnancy, menopause, hormone replacement therapy, or hormonal contraceptive use) have been associated with changes in, namely, whole-body substrate utilization (as discussed below) without an apparent direct impact on the fed-state muscle adaptive response to exercise (West et al., 2012). Specifically, during pregnancy, energy intake needs to be increased on a trimester basis: 150, 200, and $300 \mathrm{kcal} /$ day during the first, second, and third trimester in underweight women (pregravid body mass index) and 0,350 , and $500 \mathrm{kcal} / \mathrm{day}$ in normal weight women (Elliott-Sale et al., 2018). These requirements are increased further with increased exercise energy expenditure (Artal \& O'Toole, 2003).

\section{Nutritional Needs for Female Athletes}

Although the Relative Energy Deficiency in Sport paradigm (Mountjoy et al., 2014) has been linked with adverse physiologicaland performance-related outcomes in men, the synergistic effects of low EA on reproductive hormones put females particularly at risk of negative outcomes. EA in athletics is described in detail by Mountjoy et al. (2018), which covers the prevention and treatment of low EA with and without eating disorders and disordered eating.

When low EA is not an issue, the duration, intensity, and frequency of exercise are the main determinants of athletes' nutritional needs, regardless of sex. Nutrient recommendations are generally standardized according to body mass, which helps to normalize nutrient intakes across athletes of difference sizes and statures. However, it is important to recognize that the majority of sports-specific nutritional research is conducted in male athletes who generally are not only larger than their female counterparts, but also have a greater LBM-to-fat mass ratio. In addition, fluctuations in estrogen and progesterone have been shown to influence these requirements. For example, from a practical perspective, fluctuations in body composition may occur during the luteal phase of the menstrual cycle as a result of fluid retention caused by the high levels of progesterone during this phase. Athletes with high levels of LBM may experience increases in body weight (between 2 and $2.5 \mathrm{~kg}$ ), which may potentially influence performance. As such, body weight and composition should be measured at the same time during the menstrual cycle to assess true individual characteristics. Moreover, estrogen has been shown to have a proteinsparing effect by reducing the reliance on amino acid oxidation at the expense of an increase in lipolysis and fatty acid oxidation (Phillips et al., 1993), which could lead to a slightly lower protein requirement in female athletes who rely on oxidative metabolism for their discipline when this hormone is low and/or progesterone is high. Female athletes in the luteal phase have been reported to have a reduced reliance on muscle glycogen during steady state, submaximal exercise in the fasted state compared with the follicular phase and male athletes (Devries et al., 2006). This highlights differences in carbohydrate metabolism across the menstrual cycle. 
By contrast, female athletes retain the capacity to oxidize exogenous carbohydrates at a similar rate as male athletes (Wallis et al., 2006), suggesting carbohydrate fueling recommendations would be broadly similar between sexes. Ultimately, the hormonal heterogeneity of female athletes makes it difficult to produce global nutritional guidelines for female athletes and highlights the need for research representing specific female populations (e.g., eumenorrheic, amenorrheic, hormonal contraceptive users).

The sexual dimorphism in substrate metabolism is well known, although there is a dearth of female-specific data. Much of the research published on substrate metabolism and menstrual cycle and oral contraceptives during endurance exercise was conducted 20 years ago (e.g., Hackney, 1990; Suh et al., 2003), and results from these studies are conflicting. These discrepancies may be due to methodological inconsistencies in the population (e.g., type of oral contraceptive used, misidentification of menstrual cycle phase, and diverse participant characteristics such as body mass, exercise modality, and diet; Tarnopolsky, 2008). Fewer studies have been conducted on this topic in the last decade (see Castell et al., 2019), meaning that future research is still needed to overcome previous study design issues and to include newer types of hormonal contraceptives, given their rising prevalence in athletic populations (Martin et al., 2018).

Female athletes may also want to consider the effects of heavy menstrual bleeding and iron status (Pedlar, Brugnara, Bruinvels, \& Burden, 2018) and fluctuations in basal body temperature during the menstrual cycle and their effect on thermoregulation and fluid intake (Hashimoto, Ishijima, Suzuki, \& Higuchi, 2016), which may influence their nutritional practices. In addition, pregnant athletes may need to redress their energy intake (adding $>300 \mathrm{kcal} /$ day depending on exercise energy expenditure), especially carbohydrate intake, as carbohydrate usage is increased at rest and during weight- and non-weight-bearing exercise during pregnancy (Artal \& O'Toole, 2003).

In the last 10 years, few scientific papers have been devoted to the specific nutritional needs of female athletes. Although useful, many of the recent papers refer to both sexes (Heikura et al., 2017) and non-sex-specified athletes (Burkhart \& Pelly, 2016) or relate to a specific subpopulation of female exercisers (e.g., female college athletes; Shriver et al., 2013) or a single female competing in a 1-day event (Moran et al., 2011). Clearly, more research is required to elucidate the nutritional needs of female athletes; this research should not be limited to models of low EA, such as the triad and Relative Energy Deficiency in Sport, and should encompass all types of female athletes, from nonhormonal contraceptive users (e.g., eumenorrheic, amenorrheic, oligomenorrheic), to hormonal contraceptive users, to postmenopausal masters athletes.

\section{Conclusions}

Adolescent, female, and/or masters athletes have unique nutritional issues. These special population groups require support to consume a diet to meet the demands of their chosen athletic pursuit (i.e., attainment/maintenance of musculoskeletal strength, power, and/or endurance), while maintaining a focus on overall athlete health and well-being.

\section{Acknowledgments}

All authors contributed to the development of the manuscript and endorsed the submission of the final version. No conflicts of interest have been identified.

\section{References}

Aerenhouts, D., Deriemaeker, P., Hebbelinck, M., \& Clarys, P. (2011). Energy and macronutrient intake in adolescent sprint athletes: A follow-up study. Journal of Sports Sciences, 29(1), 73-82. PubMed ID: 21086211 doi:10.1080/02640414.2010.521946

Aerenhouts, D., Van Cauwenberg, J., Poortmans, J.R., Hauspie, R., \& Clarys, P. (2013). Influence of growth rate on nitrogen balance in adolescent sprint athletes. International Journal of Sport Nutrition and Exercise Metabolism, 23(4), 409-417. PubMed ID: 23475076 doi:10.1123/ijsnem.23.4.409

Aragon-Vargas, L., Wilk, B., Timmons, B., \& Bar-Or, O. (2013). Body weight changes in child and adolescent athletes during a triathlon competition. European Journal of Applied Physiology, 113(1), 233-239. doi:10.1007/s00421-012-2431-8

Artal, R., \& O'Toole, M. (2003). Guidelines of the American College of Obstetricians and Gynecologists for exercise during pregnancy and the postpartum period. British Journal of Sports Medicine, 37(1), 6-12. discussion 12. PubMed ID: 12547738 doi:10.1136/bjsm.37.1.6

Bhasin, S., Storer, T.W., Berman, N., Yarasheski, K.E., Clevenger, B., Phillips, J., . . . Casaburi, R. (1997). Testosterone replacement increases fat-free mass and muscle size in hypogonadal men. The Journal of Clinical Endocrinology \& Metabolism, 82(2), 407-413. PubMed ID: 9024227 doi:10.1210/jcem.82.2.3733

Burd, N.A., Yang, Y., Moore, D.R., Tang, J.E., Tarnopolsky, M.A., \& Phillips, S.M. (2012). Greater stimulation of myofibrillar protein synthesis with ingestion of whey protein isolate v. micellar casein at rest and after resistance exercise in elderly men. British Journal of Nutrition, 108(6), 958-962. PubMed ID: 22289570 doi:10.1017/ S0007114511006271

Burke, L.M., Cox, G.R., Culmmings, N.K., \& Desbrow, B. (2001). Guidelines for daily carbohydrate intake: Do athletes achieve them? Sports Medicine, 31(4), 267-299. PubMed ID: 11310548 doi:10.2165/00007256-200131040-00003

Burke, L.M., van Loon, L.J.C., \& Hawley, J.A. (2017). Postexercise muscle glycogen resynthesis in humans. Journal of Applied Physiology, 122(5), 1055-1067. doi:10.1152/japplphysiol.00860.2016

Burkhart, S.J., \& Pelly, F.E. (2016). Dietary intake of athletes seeking nutrition advice at a major international competition. Nutrients, $8(10)$, 638. doi:10.3390/nu8100638

Cable, N.T., \& Elliott, K.J. (2004). The influence of reproductive hormones on muscle strength. Biological Rhythm Research, 35(3), 235-244. doi:10.1080/09291010412331335788

Campbell, B., Kreider, R.B., Ziegenfuss, T., La Bounty, P., Roberts, M., Burke, D., . . . Antonio, J. (2007). International Society of Sports Nutrition position stand: Protein and exercise. Journal of the International Society of Sports Nutrition, 4, 8.

Carlsohn, A., Scharhag-Rosenberger, F., Cassel, M., Weber, J., de Guzman Guzman, A., \& Mayer, F. (2011). Physical activity levels to estimate the energy requirement of adolescent athletes. Pediatric Exercise Science, 23(2), 261-269. PubMed ID: 21633138 doi:10. 1123/pes.23.2.261

Cartee, G.D. (1994). Aging skeletal muscle: Response to exercise. Exercise and Sport Sciences Reviews, 22, 91-120. PubMed ID: 7925554 doi:10.1249/00003677-199401000-00006

Casa, D., Shirreffs, S., Cheuvront, S., \& Galloway, S.R. (2018). Fluids needs for training, competition and recovery. International Journal of Sport Nutrition and Exercise Metabolism.

Castell, L.M., Nieman, D.C., Bermon, S., \& Peeling, P. (2019). Exerciseinduced illness and inflammation: Can immunonutrition help? International Journal of Sport Nutrition and Exercise Metabolism,29(2). doi:10.1123/ijsnem.2018-0288 
Cauci, S., Buligan, C., Marangone, M., \& Francescato, M.P. (2016). Oxidative stress in female athletes using combined oral contraceptives. Sports Medicine Open, 2(1), 40. doi:10.1186/s40798-016-0064-x

Cauci, S., Francescato, M.P., \& Curcio, F. (2017). Combined oral contraceptives increase high-sensitivity C-reactive protein but not Haptoglobin in female athletes. Sports Medicine, 47(1), 175-185. PubMed ID: 27084393 doi:10.1007/s40279-016-0534-9

Centers for Disease Control and Prevention. (2011). Centers for Disease Control Prevention: Nonfatal sports and recreation heat illness treated in hospital emergency departments-United States, 2001-2009. Morbidity and Mortality Weekly Report, 60(29), 977-980.

Chen, Z., Bassford, T., Green, S.B., Cauley, J.A., Jackson, R.D., LaCroix, A.Z., . . . Margolis, K.L. (2005). Postmenopausal hormone therapy and body composition-A substudy of the estrogen plus progestin trial of the Women's Health Initiative. American Journal of Clinical Nutrition, 82(3), 651-656. PubMed ID: 16155280 doi:10.1093/ajcn/ 82.3.651

Crane, J.D., Macneil, L.G., \& Tarnopolsky, M.A. (2013). Longterm aerobic exercise is associated with greater muscle strength throughout the life span. The Journals of Gerontology, Series A: Biological Sciences and Medical Sciences, 68(6), 631-638. doi:10. 1093/gerona/gls237

Desbrow, B., McCormack, J., Burke, L.M., Cox, G.R., Fallon, K., Hislop, M., . . . Leveritt, M. (2014). Sports Dietitians Australia position statement: Sports nutrition for the adolescent athlete. International Journal of Sport Nutrition and Exercise Metabolism, 24(5), 570-584. PubMed ID: 24668620 doi:10.1123/ijsnem.2014-0031

Devries, M.C., Hamadeh, M.J., Phillips, S.M., \& Tarnopolsky, M.A. (2006). Menstrual cycle phase and sex influence muscle glycogen utilization and glucose turnover during moderate-intensity endurance exercise. American Journal of Physiology, Regulatory-Integrative and Comparative Physiology, 291(4), R1120-R1128. PubMed ID: 16690766 doi:10.1152/ajpregu.00700.2005

Di Luigi, L., Sgro, P., Fierro, V., Bianchini, S., Battistini, G., Magini, V., ... Lenzi, A. (2010). Prevalence of undiagnosed testosterone deficiency in aging athletes: Does exercise training influence the symptoms of male hypogonadism? The Journal of Sexual Medicine, 7(7), 2591-2601. PubMed ID: 20141589 doi:10.1111/j.1743-6109.2009. 01694.x

Doering, T.M., Jenkins, D.G., Reaburn, P.R., Borges, N.R., Hohmann, E., \& Phillips, S.M. (2016). Lower integrated muscle protein synthesis in masters compared with younger athletes. Medicine \& Science in Sports \& Exercise, 48(8), 1613-1618. PubMed ID: 27433963 doi: 10.1249/MSS.0000000000000935

Doering, T.M., Reaburn, P.R., Cox, G., \& Jenkins, D.G. (2016). Comparison of postexercise nutrition knowledge and postexercise carbohydrate and protein intake between Australian masters and younger triathletes. International Journal of Sport Nutrition and Exercise Metabolism, 26(4), 338-346. PubMed ID: 26696649 doi:10.1123/ ijsnem.2015-0289

Ekeland, E., Heian, F., \& Hagen, K.B. (2005). Can exercise improve self esteem in children and young people? A systematic review of randomised controlled trials. British Journal of Sports Medicine, 39(11), 792-798. discussion 792-798. PubMed ID: 16244186 doi:10.1136/bjsm.2004.017707

Elliott-Sale, K.J., Graham, A., Hanley, S.J., Blumenthal, S., \& Sale, C. (2018). Modern dietary guidelines for healthy pregnancy; maximising maternal and foetal outcomes and limiting excessive gestational weight gain. European Journal of Sport Science. Advance online publication. doi:10.1080/17461391.2018.1476591

Falk, B., Bar-Or, O., \& MacDougall, J. (1992). Thermoregulatory responses of pre-, mid-, and late-pubertal boys to exercise in dry heat.
Medicine \& Science in Sports \& Exercise, 24(6), 688-694. PubMed ID: 1602941

Falk, B., \& Dotan, R. (2008). Children's thermoregulation during exercise in the heat: A revisit. Applied Physiology, Nutrition, and Metabolism, 33, 420-427. PubMed ID: 18347699 doi:10.1139/H07-185

Gallagher, J., Ashley, P., Petrie, A., \& Needleman, I. (2018). Oral health and performance impacts in elite and professional athletes. Community Dentistry and Oral Epidemiology, 46(6), 563-568. doi:10.1111/cdoe.12392

Hackney, A.C. (1990). Effects of the menstrual cycle on resting muscle glycogen content. Hormone and Metabolic Research, 22(12), 647. PubMed ID: 2076863 doi:10.1055/s-2007-1004994

Hashimoto, H., Ishijima, T., Suzuki, K., \& Higuchi, M. (2016). The effect of the menstrual cycle and water consumption on physiological responses during prolonged exercise at moderate intensity in hot conditions. The Journal of Sport Medicine and Physical Fitness, 56(9), 951-960.

Hawkins, S., \& Wiswell, R. (2003). Rate and mechanism of maximal oxygen consumption decline with aging: Implications for exercise training. Sports Medicine, 33(12), 877-888. PubMed ID: 12974656 doi:10.2165/00007256-200333120-00002

Heikura, I.A., Burke, L.M., Mero, A.A., Uusitalo, A.L.T., \& Stellingwerff, T. (2017). Dietary microperiodization in elite female and male runners and race walkers during a block of high intensity precompetition training. International Journal of Sport Nutrition and Exercise Metabolism, 27(4), 297-304. PubMed ID: 28387576 doi:10.1123/ ijsnem.2016-0317

Hirsch, K.R., Smith-Ryan, A.E., Trexler, E.T., \& Roelofs, E.J. (2016). Body composition and muscle characteristics of division I track and field athletes. The Journal of Strength and Conditioning Research, 30(5), 1231-1238. PubMed ID: 27100166 doi:10.1519/JSC. 0000000000001203

Holwerda, A.M., Kouw, I.W., Trommelen, J., Halson, S.L., Wodzig, W.K., Verdijk, L.B., \& van Loon, L.J. (2016). Physical activity performed in the evening increases the overnight muscle protein synthetic response to presleep protein ingestion in older men. The Journal of Nutrition, 146(7), 1307-1314. PubMed ID: 27281811 doi:10.3945/jn.116.230086

Hunter, S.K., Pereira, H.M., \& Keenan, K.G. (2016). The aging neuromuscular system and motor performance. Journal of Applied Physiology, 121(4), 982-995. doi:10.1152/japplphysiol.00475.2016

Loucks, A.B. (2006). The response of luteinizing hormone pulsatility to 5 days of low energy availability disappears by 14 years of gynecological age. The Journal of Clinical Endocrinology \& Metabolism, 91(8), 3158-3164. PubMed ID: 16720651 doi:10.1210/jc.2006-0570

Loucks, A.B., Verdun, M. \& Heath, E.M. (1998). Low energy availability, not stress of exercise, alters LH pulsatility in exercising women. Journal of Applied Physiology, 84(1), 37-46.

Loureiro, L.L., Fonseca, S. Jr., Castro, N.G., Dos Passos, R.B., Porto, C.P., $\&$ Pierucci, A.P. (2015). Basal metabolic rate of adolescent modern pentathlon athletes: Agreement between indirect calorimetry and predictive equations and the correlation with body parameters. PLoS ONE, 10(11), e0142859. PubMed ID: 26569101 doi:10. 1371/journal.pone.0142859

Marcell, T.J., Hawkins, S.A., Tarpenning, K.M., Hyslop, D.M., \& Wiswell, R.A. (2003). Longitudinal analysis of lactate threshold in male and female master athletes. Medicine \& Science in Sports \& Exercise, 35(5), 810-817. PubMed ID: 12750591 doi:10.1249/01. MSS.0000065002.69572.6F

Martin, D., Sale, C., Cooper, S.B., \& Elliott-Sale, K.J. (2018). Period prevalence and perceived side effects of hormonal contraceptive use and the menstrual cycle in elite athletes. International Journal of Sports Physiology and Performance, 13(7), 926-932. PubMed ID: 29283683 doi:10.1123/ijspp.2017-0330 
Mazzulla, M., Volterman, K.A., Packer, J.E., Wooding, D.J., Brooks, J.C., Kato, H., \& Moore, D.R. (2018). Whole-body net protein balance plateaus in response to increasing protein intakes during post-exercise recovery in adults and adolescents. Nutrition \& Metabolism, 15, 62. doi:10.1186/s12986-018-0301-z

Meredith, C.N., Zackin, M.J., Frontera, W.R., \& Evans, W.J. (1989). Dietary protein requirements and body protein metabolism in endurance-trained men. Journal of Applied Physiology, 66(6), 2850-2856. doi:10.1152/jappl.1989.66.6.2850

Moore, D.R. (2014). Keeping older muscle "young" through dietary protein and physical activity. Advances in Nutrition, 5(5), 599S-607S. PubMed ID: 25469405 doi:10.3945/an.113.005405

Moran, S.T., Dziedzic, C.E., \& Cox, G.R. (2011). Feeding strategies of a female athlete during an ultraendurance running event. International Journal of Sport Nutrition and Exercise Metabolism, 21(4), 347-351. PubMed ID: 21813918 doi:10.1123/ijsnem.21.4.347

Morton, R.W., Murphy, K.T., McKellar, S.R., Schoenfeld, B.J., Henselmans, M., Helms, E., . . . Phillips, S.M. (2018). A systematic review, meta-analysis and meta-regression of the effect of protein supplementation on resistance training-induced gains in muscle mass and strength in healthy adults. British Journal of Sports Medicine, 52(6), 376-384. PubMed ID: 28698222 doi:10.1136/bjsports-2017097608

Morton, R.W., Traylor, D.A., Weijs, P.J.M., \& Phillips, S.M. (2018). Defining anabolic resistance: Implications for delivery of clinical care nutrition. Current Opinion in Critical Care, 24(2), 124-130. PubMed ID: 29389741 doi:10.1097/MCC.0000000000000488

Mountjoy, M., Sundgot-Borgen, J., Burke, L., Ackerman, K.E., Blauwet, C., Constantini, N., . . B Budgett, R. (2018). International Olympic Committee (IOC) Consensus Statement on Relative Energy Deficiency in Sport (RED-S): 2018 Update. International Journal of Sport Nutrition and Exercise Metabolism, 28, 316-331.

Mountjoy, M., Sundgot-Borgen, J., Burke, L., Carter, S., Constantini, N., Lebrun, C., . . Ljungqvist, A. (2014). The IOC consensus statement: Beyond the female athlete triad-Relative Energy Deficiency in Sport (RED-S). British Journal of Sports Medicine, 48(7), 491-497. PubMed ID: 24620037 doi:10.1136/bjsports-2014-093502

Mountjoy, M., Sundgot-Borgen, J., Burke, L., Carter, S., Constantini, N., Lebrun, C., ... Ackerman, K. (2015). RED-S CAT. Relative Energy Deficiency in Sport (RED-S) Clinical Assessment Tool (CAT). British Journal of Sports Medicine, 49(7), 421-423. PubMed ID: 25896450

Muia, E.N., Wright, H.H., Onywera, V.O., \& Kuria, E.N. (2016). Adolescent elite Kenyan runners are at risk for energy deficiency, menstrual dysfunction and disordered eating. Journal of Sports Sciences, 34(7), 598-606. PubMed ID: 26153433 doi:10.1080/ 02640414.2015.1065340

Nilwik, R., Snijders, T., Leenders, M., Groen, B.B., van Kranenburg, J., Verdijk, L.B., \& van Loon, L.J. (2013). The decline in skeletal muscle mass with aging is mainly attributed to a reduction in type II muscle fiber size. Experimental Gerontology, 48(5), 492-498. PubMed ID: 23425621 doi:10.1016/j.exger.2013.02.012

Pedlar, C.R., Brugnara, C., Bruinvels, G., \& Burden, R. (2018). Iron balance and iron supplementation for the female athlete: A practical approach. European Journal of Sport Science, 18(2), 295-305.

Petrie, H., Stover, E., \& Horswill, C. (2004). Nutritional concerns for the child and adolescent competitor. Nutrition, 20, 620-631. PubMed ID: 15212744 doi:10.1016/j.nut.2004.04.002

Phillips, S.M., Atkinson, S.A., Tarnopolsky, M.A., \& MacDougall, J.D. (1993). Gender differences in leucine kinetics and nitrogen balance in endurance athletes. Journal of Applied Physiology, 75(5), 2134-2141. doi:10.1152/jappl.1993.75.5.2134
Pizzuto, F., Bonato, M., Vernillo, G., La Torre, A., \& Piacentini, M.F. (2017). Are the world junior championship finalists for middle- and long-distance events currently competing at International Level? International Journal of Sports Physiology and Performance, 12(3), 316-321. PubMed ID: 27294320 doi:10.1123/ijspp.20150717

Proctor, D.N., Sinning, W.E., Walro, J.M., Sieck, G.C., \& Lemon, P.W. (1995). Oxidative capacity of human muscle fiber types: Effects of age and training status. Journal of Applied Physiology, 78(6), 2033-2038. doi:10.1152/jappl.1995.78.6.2033

Roche, D., Rowland, T., Garrard, M., Marwood, S., \& Unnithan, V. (2010). Skin microvascular reactivity in trained adolescents. European Journal of Applied Physiology, 108, 1201-1208. PubMed ID: 20033203 doi:10.1007/s00421-009-1328-7

Rowland, T., Hagenbuch, S., Pober, D., \& Garrison, A. (2008). Exercise tolerance and thermoregulatory responses during cycling in boys and men. Medicine \& Science in Sports \& Exercise, 40(2), 282-287. PubMed ID: 18202574 doi:10.1249/mss.0b013e31815a95a7

Sawyer, S.M., Afifi, R.A., Bearinger, L.H., Blakemore, S.J., Dick, B., Ezeh, A.C., \& Patton, G.C. (2012). Adolescence: A foundation for future health. The Lancet, 379(9826), 1630-1640. PubMed ID: 22538178 doi:10.1016/S0140-6736(12)60072-5

Shriver, L.H., Betts, N.M., \& Wollenberg, G. (2013). Dietary intakes and eating habits of college athletes: Are female college athletes following the current sports nutrition standards? Journal of American College Health, 61(1), 10-16. PubMed ID: 23305540 doi:10.1080/07448481. 2012.747526

Somboonwong, J., Sanguanrungsirikul, S., \& Pitayanon, C. (2012). Heat illness surveillance in schoolboys participating in physical education class in tropical climate: An analytical prospective descriptive study. BMJ Open, 2(4), e000741. PubMed ID: 22773535 doi:10.1136/ bmjopen-2011-000741

Suh, S.H., Casazza, G.A., Horning, M.A., Miller, B.F., \& Brooks, G.A. (2003). Effects of oral contraceptives on glucose flux and substrate oxidation rates during rest and exercise. Journal of Applied Physiology, 94(1), 285-294. doi:10.1152/japplphysiol.00693.2002

Sundgot-Borgen, J., Meyer, N.L., Lohman, T.G., Ackland, T.R., Maughan, R.J., Stewart, A.D., \& Muller, W. (2013). How to minimise the health risks to athletes who compete in weight-sensitive sports review and position statement on behalf of the Ad Hoc Research Working Group on body composition, health and performance, under the auspices of the IOC Medical Commission. British Journal of Sports Medicine, 47(16), 1012-1022. PubMed ID: 24115480 doi:10. 1136/bjsports-2013-092966

Tanaka, H., \& Seals, D.R. (2003). Invited review: Dynamic exercise performance in Masters athletes: Insight into the effects of primary human aging on physiological functional capacity. Journal of Applied Physiology, 95(5), 2152-2162. doi:10.1152/japplphysiol.00320.2003

Tarnopolsky, M.A. (2008). Sex differences in exercise metabolism and the role of 17-beta estradiol. Medicine \& Science in Sports \& Exercise, 40(4), 648-654. PubMed ID: 18317381 doi:10.1249/MSS. 0b013e31816212ff

Torstveit, M.K., Rosenvinge, J.H., \& Sundgot-Borgen, J. (2008). Prevalence of eating disorders and the predictive power of risk models in female elite athletes: A controlled study. Scandinavian Journal of Medicine \& Science in Sports, 18(1), 108-118. PubMed ID: 17490455 doi:10.1111/j.1600-0838.2007.00657.x

Torun, B. (2005). Energy requirements of children and adolescents. Public Health Nutrition, 8(7A), 968-993. PubMed ID: 16277815 doi:10. 1079/PHN2005791

Trappe, S., Gallagher, P., Harber, M., Carrithers, J., Fluckey, J., \& Trappe, T. (2003). Single muscle fibre contractile properties in young and old 
men and women. The Journal of Physiology, 552(1), 47-58. doi: 10.1113/jphysiol.2003.044966

Trappe, S.W., Costill, D.L., Fink, W.J., \& Pearson, D.R. (1995). Skeletal muscle characteristics among distance runners: A 20-yr follow-up study. Journal of Applied Physiology, 78(3), 823-829. doi:10.1152/ jappl.1995.78.3.823

Traustadottir, T., Harman, S.M., Tsitouras, P., Pencina, K.M., Li, Z., Travison, T.G., . . . Storer, T.W. (2018). Long-term testosterone supplementation in older men attenuates age-related decline in aerobic capacity. The Journal of Clinical Endocrinology \& Metabolism, 103(8), 2861-2869. PubMed ID: 29846604 doi:10.1210/jc.201701902

Trommelen, J., Kouw, I.W.K., Holwerda, A.M., Snijders, T., Halson, S.L., Rollo, I., . . . van Loon, L.J.C. (2018). Presleep dietary proteinderived amino acids are incorporated in myofibrillar protein during postexercise overnight recovery. American Journal of PhysiologyEndocrinology and Metabolism, 314(5), E457-E467. PubMed ID: 28536184 doi:10.1152/ajpendo.00273.2016

Venables, M.C., Shaw, L., Jeukendrup, A.E., Roedig-Penman, A., Finke, M., Newcombe, R.G., . . Smith, A.J. (2005). Erosive effect of a new sports drink on dental enamel during exercise. Medicine \& Science in
Sports \& Exercise, 37(1), 39-44. PubMed ID: 15632665 doi:10. 1249/01.MSS.0000150017.74892.F5

Wallis, G.A., Dawson, R., Achten, J., Webber, J., \& Jeukendrup, A.E. (2006). Metabolic response to carbohydrate ingestion during exercise in males and females. American Journal of Physiology-Endocrinology and Metabolism, 290(4), E708-E715. PubMed ID: 16278245 doi:10. 1152/ajpendo.00357.2005

West, D.W., Burd, N.A., Churchward-Venne, T.A., Camera, D.M., Mitchell, C.J., Baker, S.K., . . . Phillips, S.M. (2012). Sex-based comparisons of myofibrillar protein synthesis after resistance exercise in the fed state. Journal of Applied Physiology, 112(11), 1805-1813. doi:10.1152/japplphysiol.00170.2012

World Anti-Doping Agency. (2018). TUE physician guidelines: Male hypogonadism. Retrieved from https://www.wada-ama.org/en/resources/ therapeutic-use-exemptiontue/medical-information-to-support-thedecisions-of-tuecs-male

World Health Organization. (1983). Measuring change in nutritional status. Geneva, Switzerland: Author.

Witard, O., Garthe, I. \& Phillips, S. (2018). Protein for adaptation and physique manipulation in athletics. International Journal of Sport Nutrition and Exercise Metabolism. 